\title{
Regular Tart Cherry Intake Alters Abdominal Adiposity, Adipose Gene Transcription, and Inflammation in Obesity-Prone Rats Fed a High Fat Diet
}

\author{
E.M. Seymour, Sarah K. Lewis, Daniel E. Urcuyo-Llanes, Ignasia I. Tanone, \\ Ara Kirakosyan, Peter B. Kaufman, and Steven F. Bolling \\ Michigan Integrative Medicine Program and Section of Cardiac Surgery, \\ University of Michigan Health System, Ann Arbor, Michigan, USA
}

\begin{abstract}
Obesity, systemic inflammation, and hyperlipidemia are among the components of metabolic syndrome, a spectrum of phenotypes that can precede the development of type 2 diabetes and cardiovascular disease. Animal studies show that intake of anthocyanin-rich extracts can affect these phenotypes. Anthocyanins can alter the activity of tissue peroxisome proliferator-activated receptors (PPARs), which affect energy substrate metabolism and inflammation. However, it is unknown if physiologically relevant, anthocyanin-containing whole foods confer similar effects to concentrated, anthocyanin extracts. The effect of anthocyanin-rich tart cherries was tested in the Zucker fatty rat model of obesity and metabolic syndrome. For 90 days, rats were pair-fed a higher fat diet supplemented with either $1 \%$ (wt/wt) freeze-dried, whole tart cherry powder or with a calorie- and macronutrient-matched control diet. Tart cherry intake was associated with reduced hyperlipidemia, percentage fat mass, abdominal fat (retroperitoneal) weight, retroperitoneal interleukin-6 (IL-6) and tumor necrosis factor- $\alpha$ (TNF- $\alpha$ ) expression, and plasma IL-6 and TNF- $\alpha$. Tart cherry diet also increased retroperitoneal fat PPAR- $\alpha$ and PPAR $-\gamma$ mRNA $(P=.12)$, decreased IL-6 and TNF- $\alpha$ mRNA, and decreased nuclear factor $\kappa \mathrm{B}$ activity. In conclusion, in at-risk obese rats fed a high fat diet, physiologically relevant tart cherry consumption reduced several phenotypes of metabolic syndrome and reduced both systemic and local inflammation. Tart cherries may reduce the degree or trajectory of metabolic syndrome, thereby reducing risk for the development of type 2 diabetes and heart disease.
\end{abstract}

KEY WORDS: $\bullet$ anthocyanins $\bullet$ anti-inflammation $\bullet$ diabetes $\bullet$ nuclear factor $\boldsymbol{\kappa} B \cdot$ peroxisome proliferator-activated receptor

\section{INTRODUCTION}

O BESITY, HYPERLIPIDEMIA, and systemic inflammation are among several clinical parameters of prediabetes of "metabolic syndrome," and these phenotypes are positively correlated with the incidence of type 2 diabetes and cardiovascular disease. ${ }^{1}$ Fruit and vegetable intake is inversely correlated with cardiovascular morbidity and mortality. ${ }^{2-4}$ Furthermore, fruits and vegetables contain non-nutritive phytochemicals that may contribute to their health-promoting effects.

Anthocyanins are a major subclass of phytochemical flavonoids that are principally found in red-, blue-, and purple-pigmented fruits and vegetables. Several studies have suggested that anthocyanin-rich botanical extracts can modify lipid metabolism in vitro and can reduce hyperlipidemia in vivo ${ }^{5-10}$ Reductionistic approaches using in vitro approaches and/or isolated phytochemicals can attempt to

Manuscript received 24 October 2008. Revision accepted 10 December 2008.

Address correspondence to: Steven F. Bolling, M.D., Section of Cardiac Surgery, University of Michigan Health System, B560 MSRB2 0686, 1500 West Medical Center Drive, Ann Arbor, MI 48109, USA, E-mail: sbolling@umich.edu reveal mechanisms of effect. For example, isolated anthocyanins and anthocyanin-rich extracts have been shown to modify the activity of the peroxisome proliferator-activated receptor (PPAR). ${ }^{11,12}$ PPAR is a transcription factor that controls genes related to metabolism and inflammation, and PPAR agonist drugs are currently prescribed to reduce risk and/or manage type 2 diabetes. ${ }^{13-15}$ Tart cherries (Prunus cerasus) are a rich edible fruit source of anthocyanins. ${ }^{16,17}$ In lean rats, we previously demonstrated that inclusion of whole tart cherry powder $(1 \% \mathrm{wt} / \mathrm{wt})$ into a low fat diet significantly reduced total cholesterol and triglycerides, reduced fatty liver, and increased liver PPAR isoform mRNA. ${ }^{18}$ However, it is uncertain what disease phenotypes would be lost, sustained, or amplified if studied in an obesityprone model fed a higher fat diet. This model is increasingly relevant to our growing at-risk population with metabolic syndrome and to typical patterns of human diets, which include elevated saturated fat and cholesterol.

Zucker fatty rats develop obesity, hyperlipidemia, insulin resistance, and systemic inflammation. Importantly, Zucker fatty rats are responsive to and benefited by PPAR agonist drugs. ${ }^{19-22}$ We then tested the effect of 90-day diet provision of a high fat diet containing whole tart cherry powder. 
Table 1. Profiles of the Tart Cherry-Supplemented (CHE) Diet and Carbohydrate-Supplemented Control (CON) DieT

\begin{tabular}{|c|c|c|}
\hline & $C H E$ & $C O N$ \\
\hline \multicolumn{3}{|l|}{$\%$ of calories } \\
\hline Total protein & 20.0 & 20.0 \\
\hline Total carbohydrate & 33.0 & 33.0 \\
\hline Total fat & 47.0 & 47.0 \\
\hline $\mathrm{kCal} / \mathrm{g}$ of diet & 3.9 & 3.9 \\
\hline \multicolumn{3}{|l|}{$\mathrm{g} / \mathrm{kg}$ of diet } \\
\hline Casein & 200 & 200 \\
\hline Protein from cherry & 0.09 & 0 \\
\hline DL-Methionine & 3 & 3 \\
\hline Cornstarch & 75 & 75 \\
\hline Sucrose & 250 & 250 \\
\hline Sugar from cherry & 7.3 & 0 \\
\hline Dextrose & 0 & 3.6 \\
\hline Fructose & 0 & 3.6 \\
\hline Cellulose & 50 & 50 \\
\hline Fiber from cherry & 0.9 & 0 \\
\hline Corn oil & 25 & 25 \\
\hline Cholesterol & $860 \mathrm{ppm}$ & $860 \mathrm{ppm}$ \\
\hline Stripped lard & 178 & 178 \\
\hline Choline bitartrate & 2 & 2 \\
\hline Vitamin Mix \#300050 & 10 & 10 \\
\hline Mineral Mix \#200000 & 35 & 35 \\
\hline Vitamin C & 0.002 & 0 \\
\hline Vitamin A & $441.4 \mathrm{IU}$ & 0 \\
\hline$\alpha$-Carotene & $44 \mathrm{RE}$ & 0 \\
\hline Phosphorus & 0.013 & 0 \\
\hline Potassium & 0.11 & 0 \\
\hline Sodium & 0.015 & 0 \\
\hline
\end{tabular}

Base diet is Dyet number 102121 from Dyets, Inc. IU, international units; $\mathrm{RE}$, retinol equivalence.

We measured blood lipids, systemic inflammation as measured by plasma tumor necrosis factor- $\alpha(\mathrm{TNF}-\alpha)$ and interleukin-6 (IL-6), and percentage fat mass. Because abdominal adipose tissue is a significant source of proinflammatory cytokines, we surveyed mRNA related to inflammation in the abdominal retroperitoneal fat pad. We also measured abdominal fat levels of IL- 6 and TNF- $\alpha$ and the activity of the transcription factor nuclear factor $\kappa \mathrm{B}$ $(\mathrm{NF} \kappa \mathrm{B})$.

\section{MATERIALS AND METHODS}

\section{Animal care}

Male Zucker fatty rats (6 weeks old) were acquired from Harlan (Indianapolis, IN, USA) and were housed two per cage. Rats were housed on 12-hour light:dark cycles. At 7 weeks of age, rats were randomized to two groups $(n=12$ each): $1 \%$ tart cherry powder by weight and $0.85 \%$ additional carbohydrate (dextrose:fructose $1: 1$ ) by weight to control for the additional carbohydrate provided by the tart cherry powder. Tart cherry powder or the dextrose:fructose mixture was incorporated into powdered higher fat diet as described in Table 1 (diet number 102121, Dyets, Bethlehem, PA, USA). The cherry product was a freeze-dried powder from individually quick-frozen tart cherries, harvested in northern Michigan and prepared by VanDrunen Farms (Momence, IL, USA). Tart cherry powder nutrient analysis was conducted by VanDrunen Farms and its subsidiary Futureceuticals (Momence), and further anthocyanin analysis was conducted by our group using liquid chromatography-mass spectrometry (Table 2 ). Diets were mixed weekly, vacuum-sealed, and stored at $4{ }^{\circ} \mathrm{C}$. Rats were provided $20 \mathrm{~g}$ of diet per head/day; this was approximately $10 \%$ below ad libitum intake to ensure complete consumption and equal food intake among all rats in the study. Water was provided ad libitum. This protocol was approved by the University of Michigan's University Committee on the Use and Care of Animals.

\section{Liquid chromatography-mass spectrometry analysis of tart cherry powder}

Individually quick-frozen tart cherry powder $(1 \mathrm{~g})$ was extracted with $10 \mathrm{~mL}$ of methanol/water/acetic acid (85:15:0.5 by volume) in a $15-\mathrm{mL}$ screw-cap tube and shaken overnight in the dark at $4^{\circ} \mathrm{C}$. The sample was vortexmixed and then sonicated for 10 minutes at $25^{\circ} \mathrm{C}$ and filtered (pore size, $0.45 \mu \mathrm{m}$ ). An Alliance 2695 HPLC (Waters, Milford, MA, USA) was used to generate a binary gradient with $0.05 \%$ trifluoroacetic acid in water as the aqueous solvent (solvent $\mathrm{A}$ ) and $0.05 \%$ trifluoroacetic acid in acetonitrile as the organic modifier (solvent B). Chromatographic separation was achieved with a Gemini $5-\mu \mathrm{m}$ (particle size) C18 150- $\times 2.00-\mathrm{mm}$ (Phenomenex, Torrance, CA, USA) reverse-phase column held at $35^{\circ} \mathrm{C}$ using a flow rate of $0.19 \mathrm{~mL} /$ minute. The column was initially equilibrated to $8 \%$ solvent $\mathrm{B}$, increased to $18 \%$ solvent B over 10 minutes, $28 \%$ solvent $\mathrm{B}$ over the next 8 minutes, $40 \%$ solvent $B$ in 1 minute, $60 \%$ solvent $B$ in 3 minutes, and then returned to initial conditions. The sample chamber was cooled to $10^{\circ} \mathrm{C}$, and the injection volume was $10 \mu \mathrm{L}$. Effluent from the high-performance liquid chromatography column was directed into the electrospray ionization probe

Table 2. Tart Cherry Powder Anthocyanin Profile as Measured by Liquid Chromatography (LC)-Mass Spectrometry (MS)

\begin{tabular}{lcll}
\hline Anthocyanin & LC retention time & $M S / M S(\mathrm{~m} / \mathrm{z})$ & mg/g of dry weight \\
\hline Cyanidin 3-sophoroside & 12.668 & $611 \rightarrow 287$ & 0.0041 \\
Cyanidin 3-glucosylrutinoside & 13.618 & $757 \rightarrow 611,287$ & 0.3757 \\
Cyanidin 3-glucoside & 14.416 & $449 \rightarrow 287$ & 0.0071 \\
Cyanidin 3-rutinoside & 15.096 & $595 \rightarrow 287$ & 0.2261 \\
Peonidin 3-glucoside & 17.333 & $463 \rightarrow 301$ & 0.0388 \\
Pelargonidin & 16.959 & $271 \rightarrow 121$ & 0.0086 \\
\hline
\end{tabular}


of a TSQ Quantum Ultra AM triple quadrupole mass spectrometer (ThermoFinnigan, San Jose, CA, USA). Positive ions were generated with the following parameters: spray voltage, $3,000 \mathrm{~V}$; sheath gas, 40 arbitrary units; auxiliary gas, 10 arbitrary units; and capillary temperature, $250^{\circ} \mathrm{C}$. Tube lens voltages were optimized for each compound. Data were collected in centroid mode. Single reaction monitoring was used for mass analysis and quantification, with authentic standards for verification. Data analysis was performed with Xcalibur quantitation software (version 1.4 SR1, ThermoFinnigan).

\section{Dual X-ray absorptiometry (DEXA)}

Lean body mass and fat mass were measured every 4 weeks using DEXA on an Eclipse Peripheral Dexa Scanner with pDEXA Sabre software version 3.9.4 (Norland Medical Systems, Fort Atkinson, WI, USA) in research mode. Rats were anesthetized with $4 \%$ isoflurane and maintained with $1 \%$ isoflurane. After calibration, each rat was placed on the platform and scanned from nose to anus at $30 \mathrm{~mm} /$ second with a resolution of $1.0 \times 1.0 \mathrm{~mm}$. Results for percentage fat mass and lean body mass were determined relative to body weight on the day of the scan.

\section{Sample collection}

After 90 days of feeding, rats were fasted for 18 hours and sacrificed by decapitation. Trunk blood was collected in 0.6-mL capacity serum-separator tubes, allowed to clot at room temperature, and spun at $5,000 \mathrm{~g}$ for 7 minutes at $4{ }^{\circ} \mathrm{C}$. Serum was aliquoted and stored at $-80^{\circ} \mathrm{C}$ until further analysis. A further fraction of truck blood was collected in a 7-mL EDTA-containing Vacutainer ${ }^{\circledR}$ (Becton Dickinson, Franklin Lakes, NJ, USA) and spun at $4^{\circ} \mathrm{C}$ at $1,500 \mathrm{~g}$. Plasma was then aliquoted and stored at $-80^{\circ} \mathrm{C}$ until further analysis. Tissues were harvested and weighed, including heart, liver, kidneys, epididymal fat, and retroperitoneal fat. Tissues were snap-frozen in liquid nitrogen and stored at $-80^{\circ} \mathrm{C}$ until further analysis.

\section{Serum and plasma analysis}

Serum lipids and glucose were measured using the automated IDEXX VetTest ${ }^{\circledR}$ Chemistry Analyzer from IDEXX Laboratories (Westbrook, ME, USA). Plasma TNF- $\alpha$ and IL-6 were measured by immunoassay (R\&D Systems, Minneapolis, MN, USA) according to the manufacturer's instructions. $^{23}$

\section{Tissue inflammation}

A fragment of frozen retroperitoneal fat was powdered and homogenized with T-Per Solution (Pierce, Rockford, IL, USA) mixed with Complete Protease Inhibitor Mini-Tab cocktail (Roche, Indianapolis, IN, USA), according to the manufacturer's protocol. Levels of TNF- $\alpha$ and IL-6 were measured by enzyme-linked immunosorbent assay following the manufacturer's protocols (Quantikine ${ }^{\circledR}, \mathrm{R} \& \mathrm{D}$ Sys- tems). Both experimental samples and cytokine standards were assayed in duplicate, and the level of TNF- $\alpha$ and IL- 6 was calculated from the standard curve and expressed as the average pg of TNF- $\alpha$ and IL- 6 per mg of total protein. Protein concentrations were determined using a BCA Protein Assay kit (Pierce).

\section{Real-time reverse transcription polymerase chain reaction $(P C R)$}

Total RNA from frozen fragments of retroperitoneal fat was isolated with RNeasy ${ }^{\mathrm{TM}}$ Lipid Tissue Midi Kit (Qiagen, Valencia, CA, USA) following the manufacturer's protocol. Samples ( $n=4$ per group) were analyzed by real time-PCR using a custom $\mathrm{RT}^{2}$ Profiler PCR Array and its proprietary reagents (SABiosciences, Frederick, MD, USA). First, cDNA was prepared using the RT ${ }^{2}$ First Strand Kit. cDNA was then added to the RT ${ }^{2}$ qPCR Master Mix, which contains SYBR Green and a reference dye. The mixture is then added to a provided 96-well plate, which has 48 replicate wells containing preoptimized, species-specific primer sets for controls (housekeeping genes, genomic DNA control, reverse transcription control, and positive PCR control) and the experimental genes of interest (PPAR- $\alpha$, PPAR- $\gamma$, $\mathrm{NF} \kappa \mathrm{B}, \mathrm{IKB} \alpha$, IL- 6 , and TNF- $\alpha$ ). Each primer set of the array has undergone quality assurance/quality control analysis by real-time reverse transcription PCR and gel electrophoresis to confirm the generation a single gene product, with no additional peak and/or bands that would indicate primer dimer formation. Relative expression of PPAR- $\alpha$, PPAR- $\gamma$, $\mathrm{NF} \kappa \mathrm{B}, \mathrm{IKB} \alpha$, IL- 6 , and TNF- $\alpha$ was determined by the $\Delta \Delta C t$ method as described by Livak and Schmittgen. ${ }^{24} \Delta C t$ for each gene (averaged across four animals per group) was calculated relative to the average of five housekeeping genes (P1 large ribosomal protein, hypoxanthine guanine phosphoribosyl transferase, ribosomal protein L13A, lactate dehydrogenase $\mathrm{A}$, and $\beta$-actin). $\Delta \Delta C T$ was then determined as $\Delta C t$ (group 2, cherry) minus $\Delta C t$ (group 1, control), and the values were then back-transformed $\left(2^{-\Delta \Delta C t}\right)$ to calculate the fold change of each transcript.

\section{Tissue NFKB activity}

A fragment of frozen retroperitoneal fat was subjected to subcellular fractionation ( $n=6$ per group) using the technique of Kutoh et al. ${ }^{25} \mathrm{NF} \kappa \mathrm{B}$ activity was measured in both nuclear and cytosolic extracts using the high-throughput TransAM ${ }^{\mathrm{TM}}$ enzyme-linked immunosorbent assay (Active Motif, Carlsbad, CA, USA). The TransAM kit contains a 96well plate coated with immobilized oligonucleotide that contains the NF $\kappa \mathrm{B}$ consensus site $\left(5^{\prime}\right.$-GGGACTTTCC- $\left.3^{\prime}\right)$. The active form of $\mathrm{NF} \kappa \mathrm{B}$ contained in the cell fractions then binds to the oligonucleotide. The provided primary antibody recognizes an epitope on the NF $\kappa$ B subunit p65 that is only accessible when NF $\kappa \mathrm{B}$ is activated and bound to $\kappa \mathrm{B}$ consensus sites. A horseradish peroxidase-conjugated secondary antibody provides colorimetric detection of the bound complex at $450 \mathrm{~nm}$. NF $\kappa \mathrm{B}$ activity requires nuclear translocation, so the simultaneous assessment of $\mathrm{NF} \kappa \mathrm{B}$ activity 
Table 3. Serum and Plasma Measures in Rats Fed Tart Cherry-Supplemented (CHE) Diet and Carbohydrate-Supplemented Control (CON) Diet

\begin{tabular}{lcc}
\hline & CON & CHE \\
\hline Total cholesterol $(\mathrm{mg} / \mathrm{dL})$ & $207 \pm 14$ & $185 \pm 15^{*}$ \\
Total triglycerides $(\mathrm{mg} / \mathrm{dL})$ & $284 \pm 23$ & $241 \pm 18^{*}$ \\
Glucose $(\mathrm{mg} / \mathrm{dL})$ & $139 \pm 8$ & $117 \pm 7^{*}$ \\
Insulin $(\mathrm{pg} / \mathrm{mL})$ & $8.9 \pm 0.5$ & $7.1 \pm 0.5^{*}$ \\
IL-6 $(\mathrm{pg} / \mathrm{mL})$ & $289 \pm 31$ & $191 \pm 22^{*}$ \\
TNF- $\alpha(\mathrm{pg} / \mathrm{mL})$ & $43 \pm 5$ & $26 \pm 4^{*}$ \\
\hline
\end{tabular}

Data are mean \pm SEM values ( $n=12$ per group). $* P<.05$, versus CON.

in the cytosolic fraction served as a control for successful cell fractionation.

\section{Statistical methods}

Transcript differences are determined as \pm SD using the $\Delta \Delta C t$ method as described by Livak and Schmittgen,${ }^{24}$ using the PCR Array data analysis web portal of SABiosciences (http://www.sabiosciences.com/pcr/arrayanalysis.php). All other experimental values are expressed as \pm SEM and compared using a two-tailed Student's $t$ test. For all measures, a value of $P<.05$ was considered statistically significant.

\section{RESULTS}

Fasting glucose, insulin, total cholesterol, and triglyceride were significantly reduced in the tart cherry-fed animals. Plasma IL- 6 and TNF- $\alpha$ were reduced by $44 \%$ and $40 \%$, respectively (Table 3 ). Despite pair-feeding and matched caloric intake, tart cherry intake was associated with a lower body weight (Table 4). This difference was not significant until week 8 of the 12-week study. DEXA scan results indicated that by week 12 , tart cherry reduced relative fat mass $(-18 \%, P<.05)$ and increased lean body mass $(+14 \%$, $P<.05)$. These treatment results were apparent after week 4 (Table 4).

Tart cherry was associated with a nonsignificant increase in terminal heart and kidney weight but a statistically sig-

Table 4. Serial Body Weight and DeXa Measures in Rats Fed Tart Cherry-Supplemented (CHE) Diet and Carbohydrate-Supplemented Control (CON) Diet

\begin{tabular}{lcccc}
\hline & Week 0 & Week 4 & Week 8 & Week 12 \\
\hline $\begin{array}{l}\text { Body weight } \\
\text { CON }\end{array}$ & $188 \pm 9$ & $334 \pm 17$ & $445 \pm 17$ & $517 \pm 25$ \\
CHE & $191 \pm 6$ & $343 \pm 19$ & $433 \pm 22$ & $486 \pm 32^{*}$ \\
\% lean body mass & & & & \\
CON & $58 \pm 4$ & $44 \pm 2$ & $33 \pm 2$ & $26 \pm 2$ \\
CHE & $55 \pm 3$ & $47 \pm 3$ & $38 \pm 3^{*}$ & $34 \pm 2^{*}$ \\
\% fat mass & & & & \\
CON & $29 \pm 3$ & $44 \pm 2$ & $55 \pm 3$ & $63 \pm 3$ \\
CHE & $33 \pm 2$ & $41 \pm 3$ & $48 \pm 3^{*}$ & $54 \pm 4^{*}$ \\
\hline
\end{tabular}

Data are mean \pm SEM values $(n=6$ per group). $* P<.05$, versus timematched CON.
Table 5. Terminal Organ and Tissue Weights Expressed Relative to Tibial Length in Rats Fed Tart Cherry-Supplemented (CHE) DieT and Carbohydrate-Supplemented Control (CON) Diet

\begin{tabular}{|c|c|c|}
\hline & \multicolumn{2}{|c|}{$\mathrm{g} /$ tibial length $(\mathrm{cm})$} \\
\hline & $C O N$ & CHE \\
\hline Heart weight & $0.29 \pm 0.04$ & $0.35 \pm 0.04$ \\
\hline Liver weight & $6.8 \pm 0.3$ & $8.5 \pm 0.4^{*}$ \\
\hline Kidney weight & $0.9 \pm 0.1$ & $1.1 \pm 0.1$ \\
\hline Retroperitoneal fat pad weight & $6.4 \pm 0.3$ & $5.3 \pm 0.2 *$ \\
\hline Epididymal + perirenal fat pad weight & $3.9 \pm 0.2$ & $4.1 \pm 0.3$ \\
\hline
\end{tabular}

Data are mean \pm SEM values ( $n=12$ per group). $* P<.01$, versus CON.

nificant increase in liver weight (Table 5). These effects are also observed in rats given PPAR agonist drugs, which causes proliferation of cellular peroxisomes and increased organ weight. ${ }^{26-29}$ Retroperitoneal fat pad weight was reduced $(-17 \%, P<.05)$, whereas the combined epididymal fat plus perirenal fat pad weight was not significantly affected by cherry (Table 5 ).

We further explored treatment effect on the retroperitoneal fat pad. Tart cherry diet significantly reduced retroperitoneal fat expression of TNF- $\alpha$ (3.2-fold reduction, $P<.01)$ and IL-6 (3.6-fold reduction, $P<.01$ ) (Fig. 1). Gene expression in retroperitoneal fat was also altered by cherry. PPAR- $\alpha$ mRNA is significantly increased (3.4-fold, $P=.014)$ by tart cherry diet. PPAR- $\gamma$ mRNA was also increased (2.7-fold), and this change approached statistical significance $(P=.122)$. Both NF $\kappa \mathrm{B}$ and its activation inhibitor IKB $\alpha$ are reduced by cherry. IKB $\alpha$ transcription is regulated by PPARs, and reduced adipose tissue expression and activity of IKB $\alpha$ could reduce $\mathrm{NF} \kappa \mathrm{B}$-related inflammation. In fact, several $\mathrm{NF} \kappa \mathrm{B}$-regulated transcripts are expectedly reduced in retroperitoneal fat by tart cherry, including TNF- $\alpha$ (2.9-fold, $P=.006)$ and IL-6 (-4.5-fold, $P=.013$ ) (Table 6). Finally, NF $\kappa \mathrm{B}$ activity in nuclear extracts of retroperitoneal fat was significantly reduced by cherry (Fig. 2).

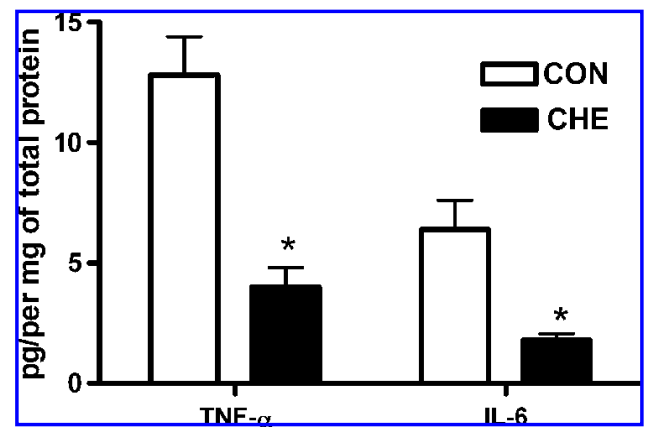

FIG. 1. Retroperitoneal fat IL-6 and TNF- $\alpha$ expression in rats fed tart cherry-supplemented (CHE) diet and carbohydrate-supplemented control (CON) diet. Data are mean \pm SEM values ( $n=6$ per group). $* P<.05$ versus $\mathrm{CON}$. 
Table 6. PCR Array Data in Expressed in Fold Change in mRNA in Retroperitoneal Fat in Rats Fed Tart Cherry Diet, Relative to Control Diet

\begin{tabular}{lcc}
\hline Gene & Fold change by cherry diet & $\mathrm{P}$ value \\
\hline PPAR- $\alpha$ & +3.4 & .014 \\
PPAR- $\gamma$ & +2.7 & .122 \\
NF $\kappa$ B & -3.8 & .130 \\
IKB $\alpha$ & -4.4 & .022 \\
TNF- $\alpha$ & -2.9 & .006 \\
IL-6 & -4.5 & .013 \\
\hline
\end{tabular}

Data are mean values ( $n=4$ per group).

\section{DISCUSSION}

Excessive fat accumulation in adipose tissue, liver, and other organs precipitates the development of metabolic changes that increase overall risk for morbidity. Abnormalities that often accompany obesity include hypertension, impaired glucose tolerance, insulin resistance, hyperinsulinemia, and dyslipidemia. Visceral obesity, which is characterized by excess fat storage in and around the abdomen, is the prime cause of the metabolic abnormalities and therefore represents an important target in the treatment of metabolic syndrome. Adipose tissue is now clearly understood to be an endocrine organ and a major site of chronic lowgrade inflammation that is associated with obesity. Adipose tissue-derived cytokines and "adipokines" play important roles in energy homeostasis, local and systemic energy inflammation, and insulin resistance. Specifically, abdominal fat is a primary source of adipokines and is therefore associated with greater pathologic consequence compared to other fat depots.

Within white adipose tissue, TNF- $\alpha$ is expressed in adipocytes, stromovascular cells, and macrophages. However, TNF- $\alpha$ produced by the adipocytes has only a local effect because it cannot be secreted; it is macrophage-produced TNF- $\alpha$ that is secreted and thus contributes to plasma TNF- $\alpha{ }^{30}$ The expression of TNF- $\alpha$ in white adipose tissue correlates with obesity and insulin resistance. ${ }^{31}$ Besides its role in white adipose tissue, TNF- $\alpha$ increases the expression of genes involved in the de novo synthesis of fatty acids and decreases mRNA transcripts involved in fatty acid oxidation

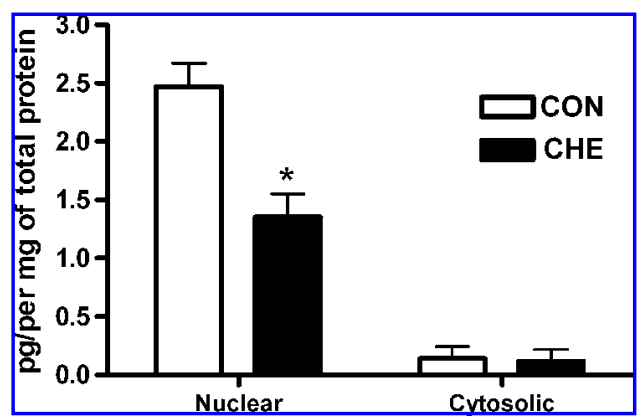

FIG. 2. Retroperitoneal fat $\mathrm{NF} \kappa \mathrm{B}$ activity in nuclear and cytosolic extracts from rats fed tart cherry-supplemented (CHE) diet and carbohydrate-supplemented control (CON) diet. Data are mean \pm SEM values ( $n=6$ per group). $* P<.05$ versus $\mathrm{CON}$. in liver. TNF- $\alpha$ also regulates the expression of other adipokines in white adipose tissue, such as IL-6. Approximately one-third of plasma IL-6 is produced by adipocytes, and IL-6 synthesis and secretion are approximately three times greater in visceral fat compared to subcutaneous fat. ${ }^{32}$ The plasma levels of IL-6 positively correlate with fat mass, obesity, impaired glucose tolerance, and insulin resistance and thus could be used to predict the development of type 2 diabetes and cardiovascular disease. ${ }^{32,33}$ IL-6, like TNF- $\alpha$, modulates the insulin sensitivity of the liver and of skeletal muscle, thereby supporting the notion that cytokines produced by the adipose tissue influence whole-body insulin sensitivity.

\section{Anthocyanins and PPAR activation}

The ligand-activated transcription factors of the PPAR family are involved in the regulation of inflammation and energy homeostasis and represent important targets for obesity, obesity-induced inflammation, and metabolic syndrome. The PPAR isoforms $(\alpha, \gamma$, and $\delta)$ share a common mode of action that involves heterodimerization with the nuclear receptor retinoid $\mathrm{X}$ receptor and subsequent binding to specific PPAR-responsive elements in the promoter region of target genes.

In abdominal fat, we observed here that cherry intake reduced inflammation and reduced expression of inflammation-related genes. This effect may be related to bioavailable tart cherry anthocyanin effects on adipose PPARs. Current results show that the cherry-enriched diet was associated with enhanced PPAR isoform mRNA in retroperitoneal fat. The effect of tart cherry on PPAR isoforms is supported by previous findings with concentrated anthocyanins or anthocyanin-rich botanical extracts. Munoz-Espada and Watkins ${ }^{11}$ showed in prostate cancer cells that cyanidin increases PPAR- $\gamma$ expression. Xia et al. ${ }^{12}$ showed that isolated anthocyanins induced cholesterol efflux from macrophages in a PPAR- $\gamma$-dependent manner and that anthocyanins increased both PPAR- $\gamma$ expression and PPAR- $\gamma$ transcriptional activity in a dose-dependent fashion. Park et $a l .{ }^{9}$ showed in diabetic mice that diets enriched with anthocyanin-rich mulberry leaf extract reduced glucose, insulin, and triglyceride while increasing liver and fat tissue expression of PPAR- $\gamma$, PPAR- $\alpha$, and liver lipoprotein lipase.

In the current study, tart cherry diet was associated with significantly increased abdominal fat PPAR- $\alpha$ mRNA expression. PPAR- $\alpha$ affects multiple target genes involved in lipid metabolism and inflammation. We previously demonstrated in lean animals fed a low fat diet that tart cherry intake was associated with increased liver PPAR- $\alpha$ mRNA, reduced liver neutral lipid fat content, enhanced hepatic acyl-coenzyme A oxidase activity, and reduced fatty acid synthase activity. ${ }^{18}$ In the current model, the effect of tart cherry intake on reduced body weight, total fat mass, hyperlipidemia, abdominal fat mass, and inflammation may be derived from one of more of these PPAR- $\alpha$-related mechanisms. PPAR- $\alpha$ agonists have a clear anorexic effect resulting in decreased food intake, ${ }^{34}$ but the pair-feeding 
paradigm used here effectively eliminates that parameter from the possible mechanisms of effect. The mechanisms of PPAR effect on inflammation is likely multifaceted. PPAR- $\alpha$ activation reduces adipocyte size, ${ }^{35}$ and smaller adipocytes secrete less inflammatory cytokines versus larger adipocytes. PPAR- $\alpha$ activation also enhances the transcription of an inhibitor of pro-inflammatory $\mathrm{NF} \kappa \mathrm{B}, \operatorname{IKB} \alpha$, a PPAR-regulated transcript that limits the nuclear translocation and subsequent activation of $\mathrm{NF} \kappa \mathrm{B}$. Additionally, PPAR activation may result in systemic events likely originating from liver, such as altered hepatic production of proinflammatory acute-phase proteins.

In the current study, tart cherry diet was also associated with increased abdominal fat PPAR- $\gamma$ mRNA expression. Although the degree of change approached statistical significance $(P=.122)$, the difference may still carry biological significance. We previously demonstrated in lean animals fed a low fat diet that tart cherry intake increased liver PPAR- $\gamma$ mRNA. ${ }^{18}$ PPAR- $\gamma$ regulates genes important for adipogenesis, lipid metabolism, and glucose control. ${ }^{36-42}$ Because we observed reduced rather than enhanced fat mass, the lipid oxidation-promoting effects of PPAR- $\alpha$ agonism appear to have overcome the effects of PPAR- $\gamma$ agonism on lipid balance. Similar to PPAR- $\alpha$, PPAR- $\gamma$ is involved in governing the inflammatory response. Inflammatory adipokines mainly originate from macrophages residing within adipose tissue. PPAR- $\gamma$ agonists can alter macrophage phenotype from "classically activated," proinflammatory macrophages to the "alternatively activated," anti-inflammatory phenotype, ${ }^{43}$ and PPAR- $\gamma$ agonists may also induce macrophage-specific cell death. ${ }^{44}$ Finally, PPAR $-\gamma$ activation could alter downstream $\mathrm{NF} \kappa \mathrm{B}$ activity and the resulting pro-inflammatory genes, as is found with PPAR- $\alpha$ activation.

In correlation with effects on PPARs, cherry diet was associated with reduced retroperitoneal fat nuclear $\mathrm{NF} \kappa \mathrm{B}$. Because $N F \kappa B$ is a vital regulator of inflammation, including the expression of TNF- $\alpha$ and IL- 6 , the diet effect on $\mathrm{NF} \kappa \mathrm{B}$ may be responsible for the reduced expression of tissue TNF- $\alpha$ and IL-6 observed here (as shown in Fig. 1). However, we cannot rule out the involvement of additional transcription factors in this effect, such as activator protein 1 . As TNF- $\alpha$ and IL- 6 are regulated by multiple transcription factors, a broader assessment of transcription factor activation in the fat tissue is warranted. Also, because whole fragments of adipose tissue were analyzed, it is uncertain which cell types within the retroperitoneal fat were most affected. For example, cherry diet could have affected $\mathrm{NF} \kappa \mathrm{B}$ activity in adipocytes, resident macrophages, and/or endothelial cells. However, the collective result is clearthe addition of tart cherry reduced inflammation in retroperitoneal fat. The determination of affected cell subtypes requires further investigation.

\section{Results in context}

The current study uses an anthocyanin-rich whole food. However, the results may be impacted by the complex polypharmacy of diverse bioavailable cherry phytochemicals and by their varied sugar moieties, which affect absorption, distribution, metabolism, and excretion. Available literature is sparse when specifically relating whole foods containing anthocyanins to the phenotypes of obesity, hyperlipidemia, insulin resistance, glucose tolerance, and inflammation. We previously reported that intake of tart cherry $(1 \% \mathrm{wt} / \mathrm{wt}$ of diet) significantly reduced fasting glucose, insulin, total cholesterol, and triglyceride in the lean Dahl-salt sensitive rat model. ${ }^{18}$ Prior et al.$^{45}$ examined the effect of anthocyanin-rich whole blueberry and strawberry consumption on dietary fat-induced obesity. Mice were fed a diet containing $10 \%, 45 \%$, or $60 \%$ kilocalories from fat, with or without freeze-dried whole berry powders at $10 \%$ (wt/wt) of diet. Animals were fed ad libitum, and after 80 days, blueberry-fed mice had $14 \%$ higher body weight, $27 \%$ higher percentage body fat, and $32 \%$ higher perigonadal (epididymal) fat weight than controls. Strawberry-fed mice had $1 \%$ higher body weight and $11 \%$ higher percentage body fat but no change in epididymal fat weight versus control. However, parallel studies using matched content of their respective isolated berry anthocyanins showed reduced body weight and reduced percentage body fat. This difference between whole fruit and extract was evident despite the matched carbohydrate-derived calories and total calorie content per gram between diets. The difference between in vivo effects of the whole berry and isolated anthocyanins is unknown. The specific profile of sugars present in the whole foods and the presence of other phytochemicals may alter bioavailability and in vivo effects. In addition, a pair-feeding approach, as we used in the current study, may be required to eliminate the confounder of food intake. For example, whole blueberry-fed rats ate roughly $12 \%$ more calories per day than control rats. Given the length of the study, this may have contributed to weight gain or adiposity. However, the whole strawberry diet increased percentage body fat in the absence of greater average daily food intake, showing further diverging effects between the fruits. Indeed, the bioavailability and in vivo effects of anthocyanin-containing fruits are not universal, which requires detailed comparative studies like those of Prior et al. ${ }^{45}$ and Joseph and co-workers. ${ }^{46,47}$

Studies with anthocyanin-rich extracts tend to support our current results. Tsuda et al. ${ }^{48}$ showed that in high-fat fed mice, an anthocyanin-rich extract from purple corn significantly reduced fat mass, hyperlipidemia, hyperinsulinemia, and blood glucose. The anthocyanin extract-enriched diet also significantly reduced tissue lipid accumulation and the activity of enzymes that promote fat storage. Xia et al. ${ }^{8,49}$ showed in atherosclerosis-prone mice that diets supplemented with an anthocyanin-rich extract from black rice significantly reduced atherosclerosis, total cholesterol, triglyceride, and tissue cholesterol and increased high-density lipoproteins. Jayaprakasam et al. ${ }^{50}$ conducted a study in mice using Cornelian "cherry." This is not a true cherry of the agriculturally employed Prunus species, but is rather the red fruit of an ornamental dogwood tree (Cornus mas). These researchers reported that $\mathrm{C} 57 \mathrm{Bl} / 6$ mice ingesting 
Cornelian cherry-derived anthocyanin extract with a highfat diet showed a significant decrease in weight gain and hepatic lipid accumulation while maintaining blood glucose control. Our findings in a whole-food model reflect those obtained with anthocyanin-rich botanical extracts. However, we cannot exclude the benefits of other tart cherryderived phytochemicals, including quercetin, melatonin, isorhamnetin, and kaempferol. These compounds may exert independent or synergistic effects towards our observed phenotypes.

In summary, tart cherry-enriched diets were associated with significantly reduced body weight, abdominal fat, reduced blood lipids, reduced plasma inflammation, and reduced fasting glucose. In addition, tart cherry intake was associated with increased expression of PPAR isoforms and PPAR-related genes in abdominal fat, reduced abdominal fat IL- 6 and TNF- $\alpha$, and reduced $\mathrm{NF} \kappa \mathrm{B}$ activity. Future studies will histologically examine the abdominal fat for the effect of tart cherry on macrophage presence and on the size and number of adipocytes; these parameters affect the levels of both local and systemic adipokines. As a rich whole-food source of anthocyanins, tart cherry-enriched diets may modify several key risk indicators for type 2 diabetes. Further studies are needed in human subjects with metabolic syndrome to ascertain the degree and spectrum of tart-cherry derived clinical benefits.

\section{ACKNOWLEDGMENTS}

This study was funded by an unrestricted grant from the Cherry Research Committee of the Cherry Marketing Institute (Lansing, MI, USA). The Cherry Marketing Institute did not participate in data analysis or manuscript preparation.

\section{AUTHOR DISCLOSURE STATEMENT}

E.M.S., A.K., and S.F.B. have partial salary and/or supply support by an unrestricted grant from the Cherry Research Committee of the Cherry Marketing Institute (Lansing, MI, USA). S.K.L., D.E.U.-L., and I.I.T. have no competing financial interests.

\section{REFERENCES}

1. Grundy SM, Hansen B, Smith SC Jr, Cleeman JI, Kahn RA: Clinical management of metabolic syndrome: report of the American Heart Association/National Heart, Lung, and Blood Institute/American Diabetes Association conference on scientific issues related to management. Arterioscler Thromb Vasc Biol 2004;24:e19-e24.

2. Brunner EJ, Mosdol A, Witte DR, et al.: Dietary patterns and $15-\mathrm{y}$ risks of major coronary events, diabetes, and mortality. $\underline{A m}$ J Clin Nutr 2008;87:1414-1421.

3. Bazzano LA, He J, Ogden LG, et al:: Fruit and vegetable intake and risk of cardiovascular disease in US adults: the first National Health and Nutrition Examination Survey Epidemiologic Followup Study. Am J Clin Nutr 2002;76:93-99.
4. Mink PJ, Scrafford CG, Barraj LM, et al.: Flavonoid intake and cardiovascular disease mortality: a prospective study in postmenopausal women. Am J Clin Nutr 2007;85:895-909.

5. Cignarella A, Nastasi M, Cavalli E, Puglisi L: Novel lipid-lowering properties of Vaccinium myrtillus L. leaves, a traditional antidiabetic treatment, in several models of rat dyslipidaemia: a comparison with ciprofibrate. Thromb Res 1996;84:311-322.

6. Finne Nielsen IL, Elbol Rasmussen S, Mortensen A, et al.: Anthocyanins increase low-density lipoprotein and plasma cholesterol and do not reduce atherosclerosis in Watanabe Heritable Hyperlipidemic rabbits. Mol Nutr Food Res 2005;49:301-308.

7. Kadar A, Robert L, Miskulin M, et al.: Influence of anthocyanoside treatment on the cholesterol-induced atherosclerosis in the rabbit. Paroi Arterielle 1979;5:187-205.

8. Xia X, Ling W, Ma J, et al.: An anthocyanin-rich extract from black rice enhances atherosclerotic plaque stabilization in apolipoprotein E-deficient mice. J Nutr 2006;136:2220-2225.

9. Park MY, Lee KS, Sung MK: Effects of dietary mulberry, Korean red ginseng, and banaba on glucose homeostasis in relation to PPAR-alpha, PPAR-gamma, and LPL mRNA expressions. Life Sci 2005;77:3344-3354.

10. Valcheva-Kuzmanova S, Kuzmanov K, Mihova V, et al.: Antihyperlipidemic effect of Aronia melanocarpa fruit juice in rats fed a high-cholesterol diet. Plant Foods Hum Nutr 2007;62:19-24.

11. Munoz-Espada AC, Watkins BA: Cyanidin attenuates PGE2 production and cyclooxygenase-2 expression in LNCaP human prostate cancer cells. J Nutr Biochem 2006;17:589-596.

12. Xia M, Hou M, Zhu $\mathrm{H}$, et al.: Anthocyanins induce cholesterol efflux from mouse peritoneal macrophages: the role of the peroxisome proliferator-activated receptor $\gamma$-liver $X$ receptor $\alpha$ ABCA1 pathway. J Biol Chem 2005;280:36792-36801.

13. Campbell IW: The clinical significance of PPAR gamma agonism. Curr Mol Med 2005;5:349-363.

14. Nehlin JO, Mogensen JP, Petterson I, et al:: Selective PPAR agonists for the treatment of type 2 diabetes. Ann N Y Acad Sci 2006;1067:448-453.

15. van Raalte DH, Li M, Pritchard PH, Wasan KM: Peroxisome proliferator-activated receptor (PPAR)-alpha: a pharmacological target with a promising future. Pharm Res 2004;21:15311538.

16. Blando F, Gerardi C, Nicoletti I: Sour cherry (Prunus cerasus L) anthocyanins as ingredients for functional foods. technol 2004;2004(5):253-258.

17. Chandra A, Rana J, Li Y: Separation, identification, quantification, and method validation of anthocyanins in botanical supplement raw materials by HPLC and HPLC-MS. $\underline{\text { J Agric Food }}$ Chem 2001;49:3515-3521.

18. Seymour EM, Singer AA, Kirakosyan A, et al.: Altered hyperlipidemia, hepatic steatosis, and hepatic peroxisome proliferatoractivated receptors in rats with intake of tart cherry. $\underline{\mathrm{J} \mathrm{Med} \mathrm{Food}}$ 2008;11:252-259.

19. Lanne B, Dahllof B, Lindahl C, et al.: PPARalpha and PPARgamma regulation of liver and adipose proteins in obese and dyslipidemic rodents. J Proteome Res 2006;5:1850-1859.

20. Oakes ND, Thalen P, Hultstrand,T, et al.: Tesaglitazar, a dual $\operatorname{PPAR} \alpha / \gamma$ agonist, ameliorates glucose and lipid intolerance in obese Zucker rats. Am J Physiol Regul Integr Comp Physiol 2005;289:R938-R946.

21. Fu J, Oveisi F, Gaetani S, Lin E, Piomelli D: Oleoylethanolamide, an endogenous PPAR-alpha agonist, lowers body weight 
and hyperlipidemia in obese rats. Neuropharmacology 2005;48: 1147-1153.

22. Dana SL, Hoener PA, Bilakovics JM, et al.: Peroxisome proliferator-activated receptor subtype-specific regulation of hepatic and peripheral gene expression in the Zucker diabetic fatty rat. Metabolism 2001;50:963-971.

23. Kirakosyan A, Seymour E, Kaufman PB, et al.: Antioxidant capacity of polyphenolic extracts from leaves of Crataegus laevigata and Crataegus monogyna (hawthorn) subjected to drought and cold stress. J Agric Food Chem 2003;51:3973-3976.

24. Livak KJ, Schmittgen TD: Analysis of relative gene expression data using real-time quantitative PCR and the 2(-Delta Delta $\mathrm{C}_{\mathrm{T}}$ ) method. Methods 2001;25:402-408.

25. Kutoh E, Ongenae N, Claeskens A, et al.: A putative white adipose tissue specific nuclear orphan receptor that interacts with the cAMP-response element of the human beta3-adrenergic receptor gene. Mol Cell Endocrinol 2000;165:85-95.

26. Donnelly R, Plato PA, Chang H, Reaven GM: Effects of gemfibrozil on triglyceride metabolism in Dahl salt-sensitive rats. J Pharmacol Exp Ther 1994;270:809-813.

27. Kurowski TG, Saha AK, Cunningham BA, et al.: Malonyl coenzyme A and adiposity in the Dahl salt-sensitive rat: effects of pioglitazone. Metabolism 1996;45:519-525.

28. O’Donnell MP, Kasiske BL, Katz SA, Schmitz PG, Keane WF: Lovastatin but not enalapril reduces glomerular injury in Dahl salt-sensitive rats. Hypertension 1992;20:651-658.

29. Wilson TW, Alonso-Galicia M, Roman RJ: Effects of lipidlowering agents in the Dahl salt-sensitive rat. Hypertension 1998;31:225-231.

30. Weisberg SP, Hunter D, Huber R, et al.: CCR2 modulates inflammatory and metabolic effects of high-fat feeding. $\underline{J \text { Clin }}$ Invest 2006;116:115-124.

31. Winkler G, Kiss S, Keszthelyi L, et al.: Expression of tumor necrosis factor (TNF)-alpha protein in the subcutaneous and visceral adipose tissue in correlation with adipocyte cell volume, serum TNF-alpha, soluble serum TNF-receptor-2 concentrations and C-peptide level. Eur J Endocrinol 2003;149:129-135.

32. Fried SK, Bunkin DA, Greenberg AS: Omental and subcutaneous adipose tissues of obese subjects release interleukin-6: depot difference and regulation by glucocorticoid. $\underline{J \text { Clin Endocrinol }}$ Metab 1998;83:847-850.

33. Bastard JP, Maachi M, Van Nhieu JT, et al:: Adipose tissue IL-6 content correlates with resistance to insulin activation of glucose uptake both in vivo and in vitro. $\underline{J \text { Clin Endocrinol Metab }}$ 2002;87:2084-2089.

34. Larsen PJ, Jensen PB, Sorensen RV, et al:: Differential influences of peroxisome proliferator-activated receptors gamma and -alpha on food intake and energy homeostasis. Diabetes 2003;52:2249 2259.

35. Li P, Zhu Z, Lu Y, Granneman JG: Metabolic and cellular plasticity in white adipose tissue II: role of peroxisome proliferatoractivated receptor-alpha. Am J Physiol Endocrinol Metab 2005; 289:E617-E626.
36. Gee MK, Zhang L, Rankin SE, et al:: Rosiglitazone treatment improves insulin regulation and dyslipidemia in type 2 diabetic cynomolgus monkeys. Metabolism 2004;53:1121-1125.

37. Itoh $\mathrm{H}$, Doi $\mathrm{K}$, Tanaka $\mathrm{T}$, et al.: Hypertension and insulin resistance: role of peroxisome proliferator-activated receptor gamma. Clin Exp Pharmacol Physiol 1999;26:558-560.

38. Laplante M, Sell H, MacNaul KL, et al.: PPAR-gamma activation mediates adipose depot-specific effects on gene expression and lipoprotein lipase activity: mechanisms for modulation of postprandial lipemia and differential adipose accretion. Diabetes 2003;52:291-299.

39. Ramachandran U, Kumar R, Mittal A: Fine tuning of PPAR ligands for type 2 diabetes and metabolic syndrome. Mini Rev Med Chem 2006;6:563-573.

40. Yamauchi T, Hara K, Miki H, Kadowaki T: [The mechanisms by which PPAR gamma regulates fat storage and insulin sensitivity]. Nippon Rinsho 2001;59(Suppl):2489-2497.

41. Yang B, Brown KK, Chen L, et al:: Serum adiponectin as a biomarker for in vivo PPARgamma activation and PPARgamma agonist-induced efficacy on insulin sensitization/lipid lowering in rats. BMC Pharmacol 2004;4:23.

42. Zierath JR, Ryder JW, Doebber T, et al.: Role of skeletal muscle in thiazolidinedione insulin sensitizer (PPARgamma agonist) action. Endocrinology 1998;139:5034-5041.

43. Bouhlel MA, Derudas B, Rigamonti E, et al.: PPARgamma activation primes human monocytes into alternative M2 macrophages with anti-inflammatory properties. Cell Metab 2007;6: 137-143.

44. Bodles AM, Varma V, Yao-Borengasser A, et al.: Pioglitazone induces apoptosis of macrophages in human adipose tissue. J Lipid Res 2006;47:2080-2088.

45. Prior RL, Wu X, Gu L, et al.: Whole berries versus berry anthocyanins: interactions with dietary fat levels in the C57BL/6J mouse model of obesity. J Agric Food Chem 2008;56:647-653.

46. Joseph JA, Shukitt-Hale B, Denisova NA, et al:: Reversals of age-related declines in neuronal signal transduction, cognitive, and motor behavioral deficits with blueberry, spinach, or strawberry dietary supplementation. J Neurosci 1999;19:8114-8121.

47. Shukitt-Hale B, Carey AN, Jenkins D, Rabin BM, Joseph JA: Beneficial effects of fruit extracts on neuronal function and behavior in a rodent model of accelerated aging. Neurobiol Aging 2007;28:1187-1194.

48. Tsuda T, Horio F, Uchida K, Aoki H, Osawa T: Dietary cyanidin 3-O-beta-D-glucoside-rich purple corn color prevents obesity and ameliorates hyperglycemia in mice. J Nutr 2003;133:2125-2130.

49. Xia M, Ling WH, Ma J, Kitts DD, Zawistowski J: Supplementation of diets with the black rice pigment fraction attenuates atherosclerotic plaque formation in apolipoprotein $\mathrm{E}$ deficient mice. J Nutr 2003;133:744-751.

50. Jayaprakasam B, Olson LK, Schutzki RE, Tai MH, Nair MG: Amelioration of obesity and glucose intolerance in high-fat-fed C57BL/6 mice by anthocyanins and ursolic acid in Cornelian cherry (Cornus mas). J Agric Food Chem 2006;54:243-248. 
This article has been cited by:

1. Forrest H Nielsen. 2010. Magnesium, inflammation, and obesity in chronic disease. Nutrition Reviews 68:6, 333-340. [CrossRef] 